\title{
Study on Advanced Water Injection Time in Low Permeability Reservoir
}

\author{
Lijun Wang, Linli Wei \\ Department of Petroleum Engineering, Northeast Petroleum University, Daqing, China \\ E-mail:wlj196464@163.com \\ Received January 6, 2011; revised March 17, 2011; accepted April 22, 2011
}

\begin{abstract}
A certain formation pressure level must be kept due to the threshold pressure of the low-permeability reservoir during the seepage. Advanced water injection can keep the formation pressure at a higher level and keep a higher pressure gradient, which is an effective way to develop low-permeability reservoir. Based on the mechanism of advanced water injection and characteristic of porous flow in low permeability reservoir, a seepage model considering threshold pressure gradient is established to determine the formation pressure distribution at anytime as the water is injected at a constant speed. The optimum water injection time for the advanced water injection technology can be determined by using this model. The calculated result coincides basically with the numerical simulation result, which indicates that the model put forward in this paper is feasible.
\end{abstract}

Keywords: Advanced Water Injection, Injection Time, Reservoir Pressure, Threshold Pressure Gradient

\section{Introduction}

Advanced water injection technology is an effective way to develop low-permeability and extra-low-permeability reservoir, which can timely supplement formation energy, improve the formation pressure, maintain a high oil production and decrease the declining rate law marked [1-7]. Besides, it can prevent the deterioration of crude oil properties, effectively keep the oil percolating channel expedite, and enhance the water injection swept volume [8-10]. The determination of reasonable injection time and ultimate injection time of advanced water flooding is a common problem considered in developing low-permeability and extra low permeability oilfield. Presently, the parameters of advanced water flooding, such as formation pressure, injection pressure, cumulative water injection quantity, water injection intensity, injection time, etc. are mainly studied by numerical simulation technology [11-13]. Unfortunately, numerical simulation needs massive data and workload. Meanwhile, because the geologic reservoir description is not clear at the early development stage, the simulation calculation can have a great error. By applying the mathematic model of non-steady flow in low permeability reservoir and con-

*Project supported by the National Natural Science Foundation of China (Grant Nos: 50634020). sidering the pressure gradient, the mathematic model of the pressure distribution is established. With this model, the relation between the formation pressure and injection quantity is determined, and then the optimum injection quantity and injection time is figured out, so as to the pressure distribution between the water injection well and the oil production well. The pressure distribution determined by using the suggested model is basically coincided with the numerical simulation result.

\section{Principle of Advanced Water Flooding}

Advanced water flooding is an effective method for developing low permeability oilfield, which has great significance for improving the development effect of oilfield by water flooding. Advanced water flooding has several advantages [14-16]:

1) The low-permeability and fractured reservoir has fluid-solid coupling effect. Fractured system and the pore throat have extreme pressure sensitivity, and the reservoir has threshold pressure (non-Darcy flow). With advanced water flooding, formation pressure can be maintained at a high level, keeping a pressure gradient higher than the threshold pressure gradient [2]. In other words, effective driving pressure system can be established, and the low-permeability, fractured reservoir can be devel- 
oped effectively.

2) Water is injected through Injection wells before oil wells are put into production, so the balance of reservoir pressure system will not be broken. Thus, the water injected can uniformly displace the oil from the injection well to the surrounding production oil wells, which effectively improves the swept volume and displacement efficiency of the reservoir. As a result, when the wells are put into production, the formation pressure is higher than the original formation pressure, the phenomenon of formation oil degassing can be avoided or reduced, and the physical properties variation of crude oil viscosity, density and so on are avoided, which is beneficial to oil flow.

3) Generally, low-permeability oil fields are pressure-sensitive. During the development process of simultaneous or delay water injection, the formation energy can not be supplied timely and the formation pressure will decline greatly, causing the formation porosity decline, natural fracture close and permeability reduce. It is very difficult for this kind of permeability reduction to recover through raising the formation pressure, permanent formation damage will occur inevitably. With an early supplement of formation energy, a certain degree of formation pressure can be maintained by advanced water flooding, which can prevent such kind of permeability damage and improve the development effectiveness of water flooding.

\section{Instable Percolation Mathematical Model in Low Permeability Reservoir}

Percolation mathematical model considering threshold pressure gradient can be written as follows:

$$
\frac{\partial^{2} p}{\partial r^{2}}+\frac{1}{r}\left(\frac{\partial p}{\partial r}+G\right)=\frac{1}{\eta} \frac{\partial p}{\partial t}
$$

For initial condition,

$$
p\left(r_{w}, 0\right)=p_{e}
$$

For boundary condition,

$$
\begin{gathered}
\left.r\left(\frac{\partial p}{\partial r}+G\right)\right|_{r=r_{w}}=-\frac{Q \mu}{2 \pi k h} . \\
\left.\left(\frac{\partial p}{\partial r}+G\right)\right|_{r=R(t)}=0 \quad p=p_{e}(r \geq R(t))
\end{gathered}
$$

where, $p_{w}$ is bottom hole pressure, $\mathrm{Pa} ; h$ is formation thickness, $\mathrm{m} ; r$ is radius, $\mathrm{m} ; Q(t)$ is water injection rate $\mathrm{m}^{3} / \mathrm{s} ; r_{w}$ is wellbore radius, $\mathrm{m} ; p_{e}$ is initial formation pressure, $\mathrm{Pa}$; $G$ is threshold pressure gradient, $\mathrm{Pa} / \mathrm{m} ; \mu$ is fluid viscosity, $\mathrm{Pa} \cdot \mathrm{s} ; k$ is permeability, $\mathrm{m}^{2}$.

According to the mathematical model above, the for- mula of pressure distribution can be deduced:

$$
p=p_{e}+\frac{Q(t) \mu}{2 \pi k_{0} h}\left[\ln \frac{r}{R(t)}+1-\frac{r}{R(t)}\right]+G[R(t)-r]
$$

where, the movement law of actuate external boundary $R(t)$ needs to be obtained. In order to obtain $R(t)$, let's consider the case of a water injection well with constant injection volume.

When the water well is injected with constant volume, the intake volume $Q(t)$ is a constant. And here only threshold pressure gradient is considered. According to material balance equation [16]:

$$
\begin{gathered}
Q=C_{t} \frac{\mathrm{d}}{\mathrm{d} t}\left\{\pi\left[R(t)^{2}-r_{w}^{2}\right] \phi h \Delta p\right\} \\
\Delta p=p_{e}-\bar{p}
\end{gathered}
$$

Through calculation, the equation of motion can be obtained:

$$
12 \eta t=\left[R(t)^{2}-r_{w}^{2}\right] \cdot\left[1+\frac{4 \pi k_{0} h R(t) G}{Q \mu}\right]
$$

Substitute the inner boundary condition, $r=r_{w}, p-p_{w}$, into formula (4), the bottom pressure can be gotten:

$$
p_{w}=p_{e}-\frac{Q(t) \mu}{2 \pi k_{0} h}\left[\ln \frac{r_{w}}{R(t)}+1-\frac{r_{w}}{R(t)}\right]+G\left[R(t)-r_{w}\right](8)
$$

By means of trial method, actuate external boundary can be obtained, and then the reservoir pressure distribution at any time can be obtained.

\section{Application of Percolation Model in Advanced Water Flooding in Low Permeability Oilfield}

In a low-permeability oilfield, fundamental parameters are given in Table 1.

Table 1. Fundamental parameters.

\begin{tabular}{lcc}
\hline \multicolumn{1}{c}{ Parameter } & Value & Unit \\
\hline Permeability & 5.2 & $\mathrm{mD}$ \\
Water viscosity & 1 & $\mathrm{mPa}$ s \\
Porosity & 0.137 & - \\
Initial pressure & 7.3 & $\mathrm{MPa}$ \\
Effective thickness & 10 & $\mathrm{~m}$ \\
Wellbore radius & 0.1 & $\mathrm{~m}$ \\
Threshold pressure gradient & 0.032 & $\mathrm{MPa} / \mathrm{m}$ \\
Water injection & 15 & $\mathrm{~m}^{3} / \mathrm{d}$ \\
Overall compressibility factor & 12.4 & $10^{-3} \mathrm{MPa} / \mathrm{m}$ \\
\hline
\end{tabular}


The most important feature of instable percolation in low permeability reservoir is that the formation pressure or energy propagation is connected with the propagation time, namely it enlarges as time elapses [16]. As the increase of water injecting time, the area swept by injected water expands gradually and the formation pressure also increases. According to the instable infiltrating fluid mathematical model in low permeability reservoir, the external boundary affected by pressure wave in a certain injection time can be calculated. The formation pressure will decrease as the distance to water well increases (as Figure 1).

According to the boundary condition of the model, when the distance to water well is greater than or equal to the actuate boundary, the present formation pressure will maintain at the original formation pressure, 7.3 MPa. The average reservoir pressure at various advanced injection time is obtained by weighting the formation pressure within the actuate area, as shown in Table 2.

The following empirical equation [17] can be used to calculate the pressure maintenance level of advanced injection in low permeability oilfield.

$$
\eta_{s}=130.4 K^{-0.12580}
$$

where, $\eta_{s}$ is pressure level, $\%$.

The average permeability of the experimental area is $5.2 \times 10^{-3} \mu \mathrm{m}^{2}$, the calculated reasonable pressure maintenance level of this area is $106 \%$. The initial reservoir pressure is $7.3 \mathrm{MPa}$, so the appropriate pressure should be 7.74 MPa. As shown in Table 2, only when advanced injection time reaches 6 month, can the reservoir pressure be around the reasonable value of 7.74 MPa. Therefore, 6 month is the optimal advanced injection time.

\section{Comparison to Numerical Simulation Result}

Numerical simulation was implemented on synchronic and advanced water injection for 9 different injection strategy with the time of 1 to 8 months. As shown in Figure 2, formation pressure gradually ascends as the advanced injection time increases, but the increasing trend is more and more slightly.

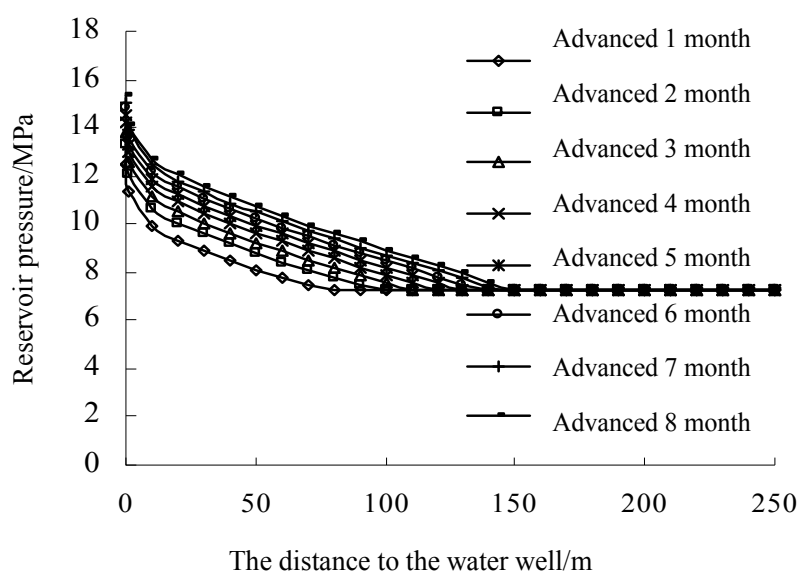

Figure 1. Reservoir pressure versus advanced injection time.

Table 2. Average reservoir pressure at various advanced injection time.

\begin{tabular}{lc}
\hline Water flood timing & Average reservoir pressure (MPa) \\
\hline Advanced 1 month & 7.38 \\
Advanced 2 month & 7.45 \\
Advanced 3 month & 7.53 \\
Advanced 4 month & 7.6 \\
Advanced 5 month & 7.68 \\
Advanced 6 month & 7.75 \\
Advanced 7 month & 7.82 \\
Advanced 8 month & 7.9 \\
\hline
\end{tabular}

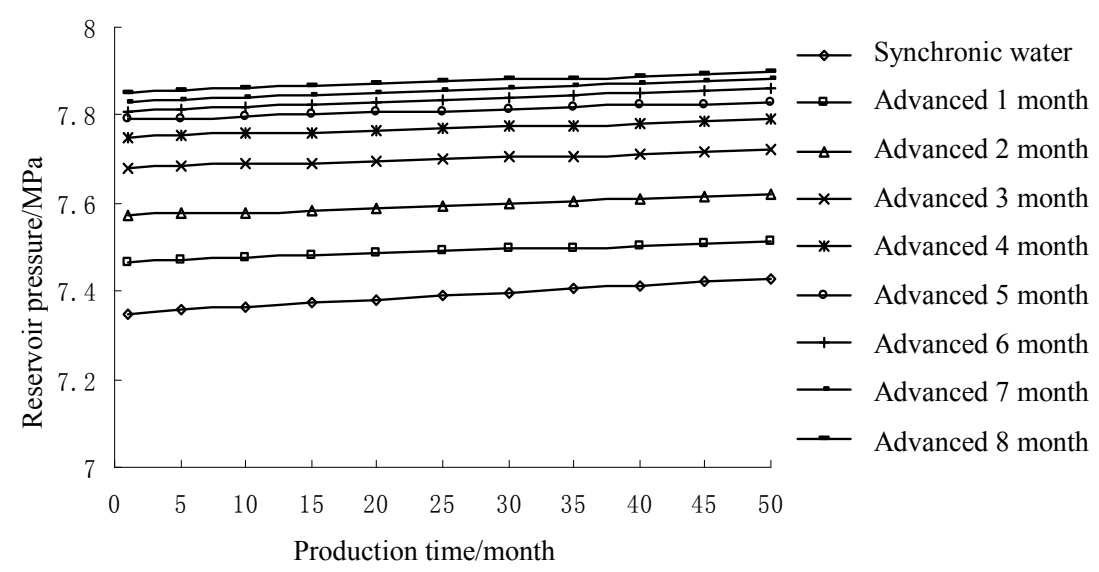

Figure 2. Pressure variation of different injection strategy in simulated area. 
Numerical simulation analysis shows that the optimum time of water injection is 6 months. With 6 months of advanced water injection, the reservoir pressure is 7.81 $\mathrm{MPa}$, and $0.51 \mathrm{MPa}$ higher than the initial reservoir pressure. When advanced injection time is more than 6 months, the variation of reservoir pressure is negligible.

\section{Conclusions}

1) Through advanced water injection, the formation pressure can be maintained at a high level, high pressure gradient can be established; the oil flow channel can be kept open to the maximum extent; the formation damage can be prevented to some extent and the development effectiveness of water flooding can be improved.

2) Based on the low-permeability unstable seepage model, the best advanced water injection time is obtained, which is consistent with the numerical simulation results, verifying the correctness of the theoretical model.

3) Advanced water injection can improve the conductivity capacity of low permeability reservoirs, so as to increase the production and enhance oil recovery. The results obtained in this paper should have an important and guiding significance to the development of low permeability reservoirs, and provide a basis to develop other similar oilfields.

\section{References}

[1] R. F. Wang, X. L. Li, B. Li, Y. H. Wang, Li. M. Kang and Z. Q. Bai, "Timing of Rational Advanced Water Injection and Limit Water Injection," Henan Petroleum, Vol. 17, No. 6, 2003, pp. 21-23.

[2] R. F. Wang, Z. Q. Song, H. Yong, L. Zhao and B. Hu, "Utilizing Advanced Water Injection to develop Low Permeability Pool," Fault-Block Oil and Gas Field, Vol. 10, No. 3, 2003, pp. 43-45.

[3] Y. T. Li, Z. Y. Liu, Q. H. Lv, X. G. Wu and Z. Y. Zhang, "Research and Application on Technology of Advance Water Flooding in Guyunji Oilfield," Special Oil and Gas Reservoirs, Vol. 14, No. 5, 2007, pp. 58-60.

[4] D. P. Li, "The Development of the Low Permeability Sandstone Oilfield," Petroleum Industry Press, Beijing, 1995, pp. 174-177.

[5] P. C. Liu, F. H. Li, K. Li and Y. D. Wang, "Advance Water Injection in Reverse Nine-Spot Well Pattern in Block 119 of Xinli Oilfield," Journal of Oil and Gas Technology, Vol. 29, No. 6, 2007, pp. 120-123.
[6] F. J. Ma, J. C. Hu, J. Zhuang, Q. L. Shi and Q. Wu, "The Application and Practice of Advanced Water Injection in Low Permeability Reservoir of XinLi," Special Oil and Gas Reservoirs, Vol. 12, No. 3, 2005, pp. 47-49.

[7] Z. Y. Zhan, X. M. Wu, X. J. Liu and H. Y. Qi, "Development Technique and Results Interpretation of Advance Water Flooding in Wuqi Oilfield," Inner Mongulia Petrochemical Industry, No. 8, 2007, pp. 191-193.

[8] J. H. Wang, "Low Permeable Oilfield to Run before to Note the Research of Water," Fault-Block Oil and Gas Field, Vol. 12, No. 3, 2005, pp. 53-54.

[9] J. X. Chen, Q. H. Huang and L. Sun, "Application of Advanced Water Flooding in Low Porosity and Permeability Oilfield," Inner Mongulia Petrochemical Industry, No. 10, 2005, pp. 102-104.

[10] Q. J. Che, J. A. Lei, Y. X. Ran and Z. Y. He, "Effects of Advanced Water Flooding in Extra-Permeability Oilfield Development," Pertroleum Geology and Oilfield Development in Daqing, Vol. 22, No. 1, 2003, pp. 20-22.

[11] C. S. Zhu, L. S. Cheng and S. J. Zhang, "Approximate Solution for Non-Steady Flow in Low-Permeability Reservoir," Journal of Southeast Petroleum University, Vol. 30, No. 4, 2008, pp. 69-72.

[12] S. Q. Li, L. S. Cheng, X. S. Li and F. Hao, "Non-Linear Seepage Flow Models of Ultra-Low Permeability Reservoirs," Petroleum Exploration and Development, Vol. 35, No. 5, 2008, pp. 606-612. doi:10.1016/S1876-3804(09)60092-6

[13] M. G. Zhao, H. F. Zhou and D. F. Chen, "Investigation and Application on Gas-Drive Development in Ultra-Low Permeability Reservoir," Journal of Hydrodynamics, Vol. 20, No. 2, 2008, pp. 254-260. doi:10.1016/S1001-6058(08)60054-2

[14] Z. D. Lei, S. Q. Cheng, X. F. Li and H. P. Xiao, “A New Method for Prediction of Productivity of Fractured Horizontal Wells Based on Non-Steady Flow," Journal of Hydrodynamics, Vol. 19, No. 4, 2007, pp. 494-500. doi:10.1016/S1001-6058(07)60145-0

[15] M. L. Zhang and Y. M. Shen, "Study and Application of Steady Flow and Unsteady Flow Mathematical Model for Channel Networks," Journal of Hydrodynamics, Vol. 19, No. 5, 2007, pp. 572-578. doi:10.1016/S1001-6058(07)60155-3

[16] Y. F. Zhai, "Fluid Mechanics in Porous Medium," Petroleum Industry Press, Beijing, 2003, pp. 61-62.

[17] D. F. Wang, Z. X. Li, J. Y. Zhao, Y. H. He and F. Hao, "Advance Water-Flooding Theory for Low-Permeability Reservoirs and Its Application," ACTA Petrolei Sinica, Vol. 28, No. 6, 2007, pp. 78-81. 